\title{
China Internet Based Academic Journals Digital Publishing Models Study
}

\author{
Xiangxing Shen ${ }^{1}$, Xiangdong $\mathrm{Li}^{1}$, Yuan Yang ${ }^{1}$, Chong Shen ${ }^{2,3}$, Kae Hsiang Kwong ${ }^{3}$ \\ ${ }^{1}$ Centre for Studies of Information Resources, Wuhan University, Wuhan, China \\ ${ }^{2}$ College of Information Science \& Technology, Hainan University, Haikou, China \\ ${ }^{3}$ Centre for Intelligent Dynamic Communications, University of Strathclyde, Glasgow, UK \\ E-mail:x.shen@whu.edu.cn \\ Received April 1, 2010; revised May 7, 2010; accepted July 20, 2010
}

\begin{abstract}
The research takes three fundamental Internet Academic Journals (IAJ), which are China National Knowledge Infrastructure (CNKI), Chongqing VIP Information Co., Ltd. (VIP) and Beijing Wanfang Data Co., Ltd. (WFD), as subjects to discuss digital publishing mechanism innovations for China's science information communication system. After introducing main Internet environment, comparing journal characteristics, and explaining publishing \& operation modes of the IAJs, the paper analyses important issues such as redundant contents, digitalization issues, illegal journals, standards construction, copyright and benefit distribution. By learning from research practices and open access, a new benefit distribution and copyright management mode based on the Third Party Agency (TPA) is proposed. Future IAJs operation modes are also discussed from the view of scientific research innovation and state of the art platform construction.
\end{abstract}

Keywords: China, Publishing Mode, Internet Academic Journals, Digital Library, Standard, Illegal Journals

\section{Introduction}

Science information communication is one of the most important stakeholders in digital publishing. In practice the information carrier plays a vital role while the traditional science information communication theory is based on the understanding of carrier's function. For example, H. Menzel's "information communication process" theory divides the process according to information carriers and A. Mikhailov's "science information communication" theory defines books, journal literatures and other paper carriers as the foundation for constructing science information communication system [1]. Each theory emphasizes that information carriers are the possibilities for science information communication. Traditional science information communication system, which was independent in form of printed publications, has gradually adapted to the coexistence with digital publications such as electronic books, IAJs, etc.

The paper is supported by National Natural Science Foundation of China Youth project "the Research of Similar Information Dissemination Dynamics under the Anti-Plagiarism Realization" (No. 60803080).

Digital publishing refers to publications published using digital technology. As digital technology evolves with the development of computer hardware and software as well communication technology, digital publishing has developed from early stage electronic publishing, desktop publishing, web publishing and network publishing to today's Internet publishing. Regardless the names, such publishing is a succeeding publications of books, journals, newspapers and magnetic medium publications including audio and video tapes, which is a brand-new cultural production and transmission mode. Supported by digital technology and carried by computer networks, digital publishing brings about a revolutionary transformation of traditional publishing forms and patterns [2].

Of various forms of digital publications, IAJ which shares traditional printed journals properties is a major tool in science information communication system. In this research the typical CNKI IAJ is taken by us as the main form of digital publishing to discuss mechanism innovation issues in China.

\section{Status Quo of IAJs in China}

\subsection{Network Environment of IAJs in China}

Two backbone networks, the China Education \& Re- 
search Network (CERNET) and China Science \& Technology Network (CSTNET) were constructed by the China state [3], as shown in Figure 1 with a description on geographical topology. The two networks are now managed by the Ministry of Education and Ministry of Science and Technology, separately. The construction, operation \& maintenance and service update of the two networks are undertaken by leading institutes such as Tsinghua University and Chinese Academy of Sciences, respectively. In 1996, the two networks were officially listed as two of four China backbone infrastructure networks by the China state council.

CERNET was finished construction in 1994 and is the first nationwide Internet backbone network in China. At present, the transmission speed of CERNET's main stream is up to 2.5 - $10 \mathrm{Gbps}$ and that of its local substream is up to $155 \mathrm{Mbps}-2.5 \mathrm{Gbps}$. The network covers more than 200 cities of 32 state provinces including autonomous regions and Hong Kong special administrative region. It physically possesses over $30,000 \mathrm{~km}$ optical fiber with independent international outreaching throughput exceeding 5 G. 10 regional centers and 38 provincial nodes are in operation with one central network center located at Tsinghua University, Beijing. The giant network also links more than 2000 universities, educational institutions and scientific research units serving over 20 million users, which becomes a fundamental and indispensable educational information platform in China [4].

CSTNET was established in 1989 as a scientific research network of Chinese Academy of Sciences and national public network. The transmission speed up of CSTNET's main trunk is up to $2.5 \mathrm{Gbps}$ to date and that of its local sub stream is up to $155 \mathrm{Mbps}-2.5 \mathrm{Gbps}$. The inter-network data exchange rate between CERNET and CSTNET is up to 2 Gbps while CSTNET's international outreaching throughput exceeds $4.5 \mathrm{G}$. Similar to CERNET, the network also covers 30 provinces, autonomous regions and Chinese Taiwan. The domestic backbone network is composed of 13 distributed city sub-centers including Beijing, Changchun, Shenyang, Shanghai, Guangzhou, Chengdu and Lanzhou, making itself another basic scientific information platform in China [5].

\subsection{Development of IAJs in China}

In 1989, Chongqing VIP issued the earliest academic digital journal in China in the form of floppy disk. In 1996, a large-scale integrated Chinese academic Journal (CD Edition) was developed by China Academic Journals Electronic Publishing House (CAJEPH) which marks the beginning of journal digital publishing in China. In 1997, WFD \& company established the first technology information WWW website. The company focused on the association between the digital publishing and Internet. In June 1998, Chinese Academic Journal (CD Edition) was officially listed on the web. The Chinese academic Journal Full-Text Database marks an important milestone and initiates a new era of IAJ publishing in China.

The National Knowledge Infrastructure and its application such as knowledge based economy, as the fourth main infrastructure after energy, transportation and telecommunication, were identified and agreed in different degree by America, Britain and other developed countries governments. Increasing attention has been also paid on China National Knowledge Infrastructure (CNKI)

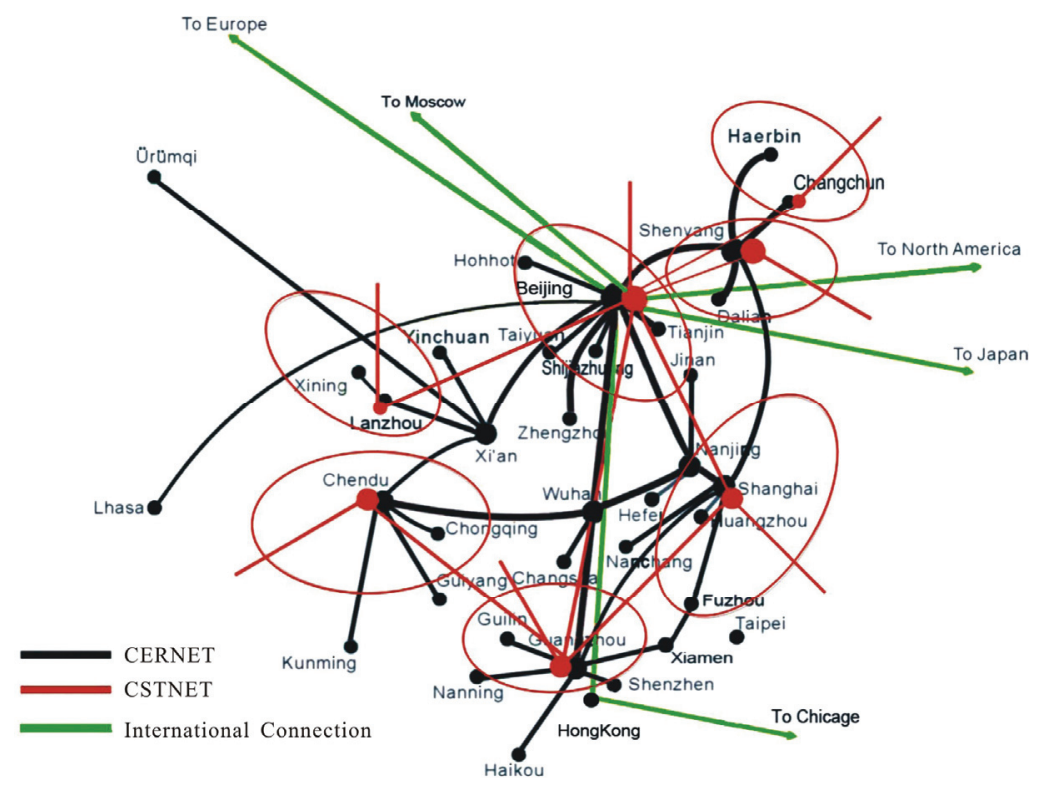

Figure 1. Topology of CERNET and CSTNET. 
in China. Under the leaderships of the Ministry of Education of the People's Republic of China (MEC), the Ministry of Science and Technology of the People's Republic of China (MSTC), General Administration of Press and Publication of the People's Republic of China (GAPPC) and other ministries or commissions of China, relying on the support from libraries, information service centers and almost all Chinese academic journal editorial boards (CAJEB), Tong Fang Knowledge \& Network Technology Co., Ltd (TKNT) has developed CNKI as a national development project with several internet editions, which promotes Chinese IAJs to an advanced level in terms of literatures volume and data collecting technologies.

The 3 IAJs VIP, CNKI (TKNT) and WFD so far have effectively collected printed journals into respective electronic journal databases by cooperating with printed journal editorial boards. These databases are formal and serialized Internet publications with electronic journal serial numbers approved by the GAPPC. Every CAJEBs is administrated by competent departments under one of the ministries or commissions under the China State Council which disburse funds to pay editorial staff's salaries and daily operation expenditures. In order to protect intellectual property right, coordinated by the GAPPC and the ministries and commissions the three organizations established copyright monitoring systems with various types of CAJEBs to mutually reuse resources between databases, which forms the basic science information communication mode based on Chinese IAJs as shown in Figure 2 .

\subsection{Status Quo of Construction of Chinese IAJ Literature Database}

After more than 20 years development, Chinese IAJ literature database market has been divided and shared by VIP, CNKI and WFD with other small-sized specialized literature databases. China now owns totally 9,468 kinds of Chinese journals.

VIP's Chinese scientific and technical journals fulltext database collects more than 20 million published literatures in over 8,000 kinds of domestic journals,

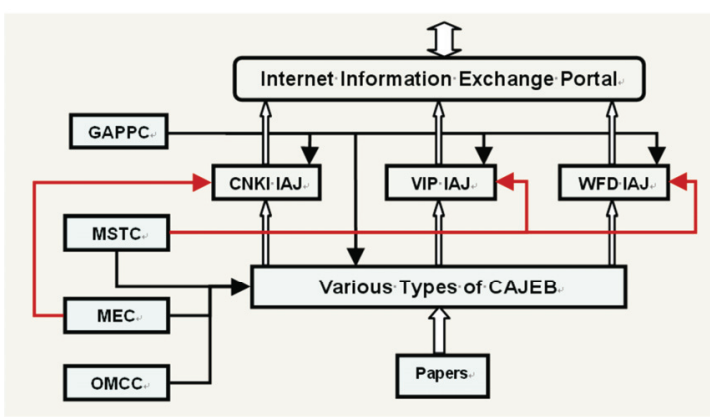

Figure 2. IAJ science information communication modes. which are divided into eight special areas: social sciences, natural sciences, engineering technology, agricultural science, medicine and hygiene, economy and management, educational science, and library and information science. It is also an important strategic partner of Google, and one of the largest cooperative Chinese content websites of Google Scholar. However, the website itself does not present any English interface, as shown in Table 1.

CNKI has experienced 3 phases of development with corresponding name changes: earlier Chinese academic journal (CD Edition), then Chinese academic journal network and currently a brand new knowledge service platform named China's Knowledge Resources Database (CKRD). Apart from accommodating academic journals, it also provides Internet publishing for a series of databases including academic conference papers, doctoral and master's thesis, newspapers and other literatures using self-developed CNKI knowledge network platform for management and data retrieval. It collects 8,893 kinds of domestic journals containing more than 23.45 million of full-text documents, covers nearly all fields such as natural sciences, engineering technology, agriculture, philosophy, medicine and humanities, social sciences, etc., as shown in Table 1. By October 2006, CNKI had already owned more than 17,000 different customers covering universities, research institutions and government organizations. It is also subscribed and frequently used by university libraries outside China such as Harvard University library and Oxford University DL, and large-scale public libraries like National DL of Singapore [6]. CNKI is therefore identified as one of the most representative IAJs in China.

WFD's Chinese digital journal group specialized in eight categories with more than 100 sub-items: philosophy, politics and law, social sciences, economy and finance, education, science, culture and art; fundamental science, medicine and hygiene, agricultural science, and industrial technology. It includes 6065 kinds of domestic journals and more than 12.9 million of full-text literatures. The website provides use-friendly feathers such as an English interface while its Chinese journals can be easily linked to various classified English subjects. However, only the Chinese interface provides the list of all journal names.

\subsection{Publishing and Operation Mode of CNKI IAJ}

The central website and eight regional exchange service centers of CNKI IAJ are established and maintained by TKNT. Figure 3 presents the topology framework and connection methods [7]. The website has been supported by two completely identical central sites established at 
CERNET and China Broadband Network (CHINANET), separately. It provides services through "resource database" and "knowledge database". It also provides jointlyconstructed resources and shared knowledge information. Each central website updates knowledge resources, fulltext service for CNKI Knowledge Network Management Service Centers and CNKI Mirror sites in different cities through KNS5.0 (Knowledge Network Service 5.0) daily. Meanwhile, the website includes internet retrieval service for institutions and individuals using CNKI knowledge resource and online digital submission service. CNKI IAJ has the following operation modes: professional customers such as universities, research institutions, public libraries, government, enterprises, secondary and primary schools purchase services by database wholesale or remote packaged database installation. The databases then established on local servers in the form of mirror sites provide service for local area network users. The subscription fee is charged per network flow, individual reader purchase and accounts download. The users can pay by dedicated CNKI cards, normal bank cards or pre-paid telecommunication cards. The organization also gets revenue from paid information and analysis, advertising and government support.

\subsection{CNKI IAJ's Publishing Institutions and Work Division}

TKNT, CAJEPH and Tsinghua Tongfang Optical Disc
Co., Ltd. (TTOD) have worked together to deliver the CNKI project. Figure 4 shows the work division undertaken by different partners for CNKI's publishing and issuing [8].

For CNKI editing, publishing and journal distribution, CAJEPH is responsible for contacting various academic journal editorial boards, university libraries, national degree authorities and conference paper publishers to obtain electronic journal publications approvals, discuss potential product, optimize journal content, etc. CAJEPH has the high-level copyright to editing all journal parts, CNKI full-text journal database and other databases; TTOD makes use of the content resources provided by the press to conduct research \& development, improve publishing process and provide online storage products and relevant techniques for CNKI distribution; TKNT provides technical support to network publishing platform promotes marketing and monitors sales.

\section{Existing Problems of Chinese IAJs and Analysis}

\subsection{Duplicated Construction Issues}

As shown in Figure 2, VIP, CNKI and WFD all fetch resources from CAJEBs. Depending on different company guidelines and operation models, they contact CAJEBs individually to obtain copyrights for publishing

Table 1. Internet database of 3 major Chinese academic journals.

\begin{tabular}{|c|c|c|c|}
\hline Content & VIP database & CNKI database & WFD database \\
\hline IAJ site & http://www.cqvip.com/ & http://www.edu.cnki.net & http://www.wanfangdata.com.cn/Default.aspx \\
\hline IAJ mirror site & http://vip.hbdlib.cn/ & $\begin{array}{l}\text { http://cnki2.lib.whu.edu. } \\
\text { cn/kns50/index.aspx }\end{array}$ & http://g.wanfangdata. com.cn/Default.aspx \\
\hline \multirow[t]{2}{*}{ Site location } & Chongqing & Beijing & Beijing \\
\hline & $\begin{array}{l}\text { CSTNET } \\
\text { non-backbone }\end{array}$ & CERNET backbone & CSTNET backbone \\
\hline Date & $1989 \sim$ & $1994 \sim$ & $1997 \sim$ \\
\hline \multirow[t]{4}{*}{ Product forms } & Web version & Web version & Web version \\
\hline & Mirror version & Mirror version & Mirror version \\
\hline & CD-ROM version & CD-ROM version & CD-ROM version \\
\hline & Traffic billing & Traffic billing & Traffic billing \\
\hline Document format & PDF & PDF or CAJ & PDF \\
\hline Journal number & 8,000 & 9,100 & 6,669 \\
\hline Journal papers & $20,000,000$ & $34,215,263$ & $14,691,014$ \\
\hline Conference papers & no & $1,351,056$ & $1,579,437$ \\
\hline $\begin{array}{l}\text { Academic disserta- } \\
\text { tion }\end{array}$ & no & $1,078,450$ & $1,625,297$ \\
\hline Google scholar & yes & no & no \\
\hline Update frequency & Daily & Daily & Weekly \\
\hline
\end{tabular}




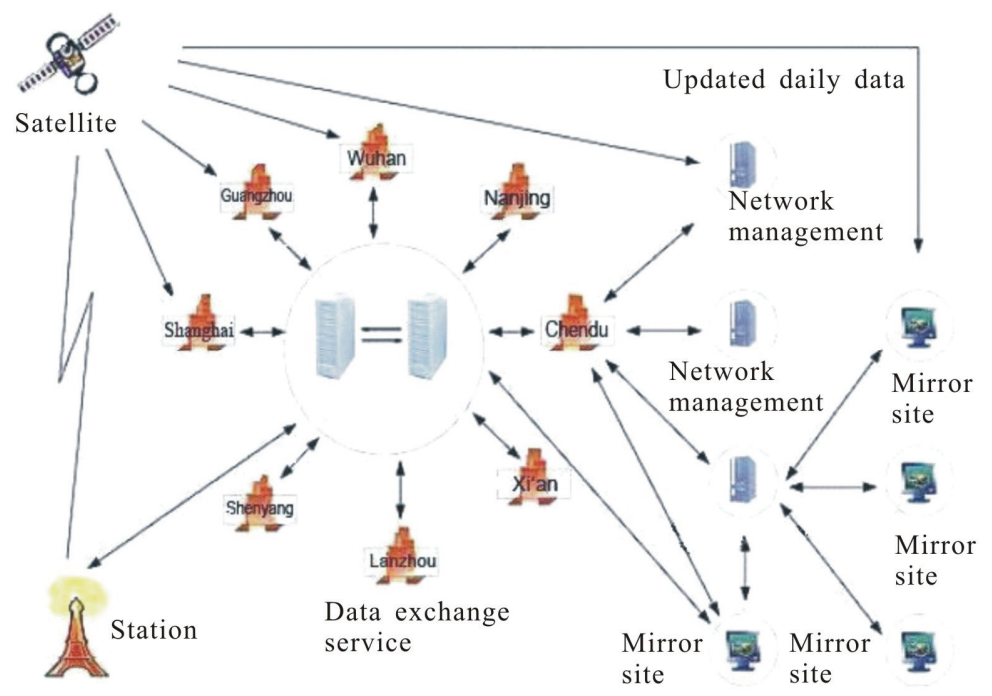

Figure 3. Topology framework of CNKI IA.

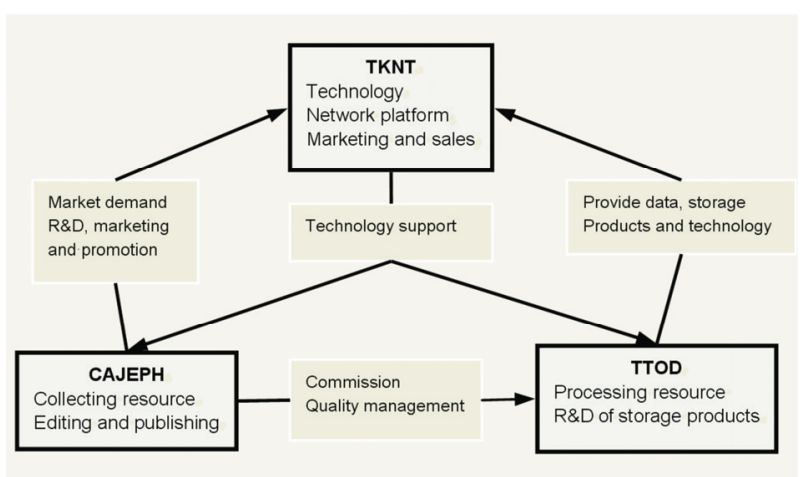

Figure 4. CNKI IAJ's publishing institutions and work division.

printed journal resources on the Internet, without know by each other. On the other hand, neither CAJEBs nor the authors aware of exclusive policy on duplicated publishing of journals and publications, which increase the possibility that more than one IAJ publish the journal and publication. The worse scenario is the same journal can be published simultaneously by three IAJs in this case, which causes resource repetition among the three IAJs. Investigating all printed journals collected by the three IAJs by the end of 2006, a literature [9] analyses the repetition through ISSN, journal names and serial numbers. It points out that 4,413 kinds of printed journals are collected at same time by all of the three IAJs, taking up $57 \%, 71 \%$ and $79 \%$ of the total journals of CNKI, VIP and WFD, respectively. Among the rest, 561, 849 and 123 kinds of printed journals are collected at same time by CNKI and VIP, CNKI and WFD, VIP and WFD, respectively. For journals which are collected only by one of the three IAJs, CNKI, VIP or WFD, the figures are $1,869,1,119$ and 170 kinds, respectively, as shown in Figure 5.
The duplicated resource construction indicates that every IAJ focuses on its own business scope under different leadership or relevant superior department. There is no mutually agreed planning or overall strategy, leading to waste in journal producing, purchasing and usage. From printed journals to electronic ones, each IAJ separately carries out editing, unpacking, scanning, checking and indexing, which directly causes duplicated production and waste in human resource, roll material and finance. The problem is there are many duplicated journals as well as exclusively collected ones simultaneously. With limited funds, universities and colleges libraries as the main purchasers have to spend a big amount to purchase electronic journals with a repetition rate over $50 \%$. And users have to use more than one IAJ to improve the scope coverage which makes their burdens heavier.

\subsection{Paper "Buy and Sell" and Illegal Academic Journal Issues}

Occasionally, you may notice advertisements for buying and selling on university campus, Bulletin Board System (BBS) and instant messaging groups. Some occupations e.g. lecturer, scientific researcher, Ph.D. student do receive random inquire on journal buying. Without a law over cyberspace, lawbreakers can do illegal paper dealings through the Internet. Since they follow an attractive strategy that papers can be written before money is paid and can guarantee the publishing once submitted, someone would buy "the product" and those papers are never peer-reviewed or with any academic standards. The illegal academic journals producers charge expensive fees to gain enormous profits. The issue also becomes very common among undergraduates and postgraduates. The changes in searching "paper ghostwrites" in 2008 can be observed by Google Trends, as shown in Figure 6. 
The map indicates that ghost written papers increased in the first half year when undergraduates, postgraduates and doctoral students were preparing for thesis/dissertation defenses, and the demand for ghost written papers decreased sharply after they graduated. The buyers are from research institutions including universities and colleges and the papers are mainly published in illegal academic journals. On average, one illegal journal publishes 169 papers per issue. From the distribution of original authors of the 169 papers, universities and colleges are the "disaster areas" which are deceived both actively and passively. The affiliation types of these first authors are shown in Figure 6. Many of them are from key Chinese universities and colleges, as shown in Figure 7.

The rapid development of the Internet and communication technology has boosted paper buy and sell business, and accelerated illegal journal publishing process. A collection of anonymous users is available behind Internet shelter, and the businesses are conducted in a hidden way. Advertisements and related links of paper selling and buying are reachable pervasively over the Internet (as shown in Figure 8, with dotted line). To date, China has neither formed a strict article responsibility check system nor popularized anti-plagiarism detection software and application. The GAPPC although has taken a series of measures to deal with the problems, e.g., it organizes stringent activities to check journals every year, published an updating list of the illegal academic journals catalogues and punished a group of lawbreakers. These measures fail to put an end or even a temporary stop of the business. Therefore, we urge major search engines and websites practically undertake their social responsibilities to enhance the capabilities of distinguishing between original papers and plagiarized ones for all journal publishers, crack down or ban paper selling and buying advertisement, and construct complete and efficient Chinese IAJ platforms.

\subsection{IAJ XML Standard Problems}

The standardization degree in current digital publishing industry in China is not high enough. Compared with those in developed countries, domestic digital publishing industry is far behind in terms of process establishment and implementation standards. China lacks an overall standardized protocol and even fails to establish the most basic standard system architecture, though we have introduced a variety of international standards for printing. Moreover, despite the improvement in establishment process for publication format, information-oriented publication and publication logistics, there still is some inefficiency. For example, for the publication format, comparatively systematic standards have been established only for printed books and journals, but not for audio, video products and electronic publications. Not to men- tion the online digital publications, the standards for the format are still to be determined and under hot debate. According to the requirements of press and publishing industry in the "11th China National Development FiveYear Plan", the research on press and publishing standard system has been listed as a key task of publishing science research. China Institute of Publishing Science has undertaken the task under the approval of the MSTC and has completed prove of concept by 2008. Besides, researches for Network Publishing Standards, Classified Standards for Publication Marketing and Normative Standards for Publication Logistics Procedure have already been initiated and will be finished in two to three years [10].

The indexing resources for full-text VIP, CNKI and WFD index are text documents such as Microsoft word documents received from CAJEBs or text documents

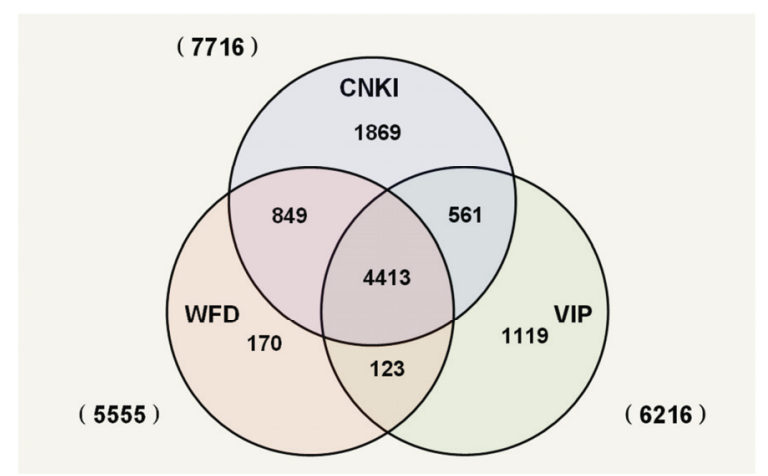

Figure 5. Repetitions of resource among CNKI, VIP and WFD.

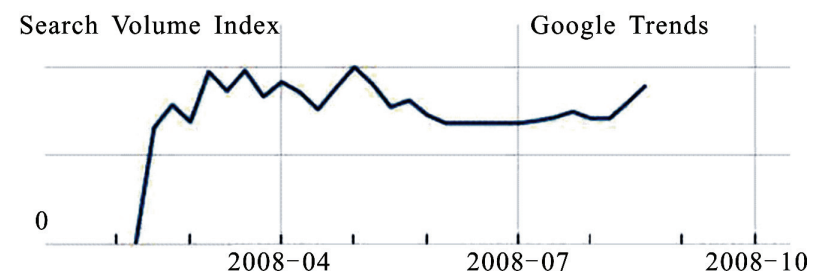

Figure 6. Search trend map of "ghost written" Chinese journal papers.

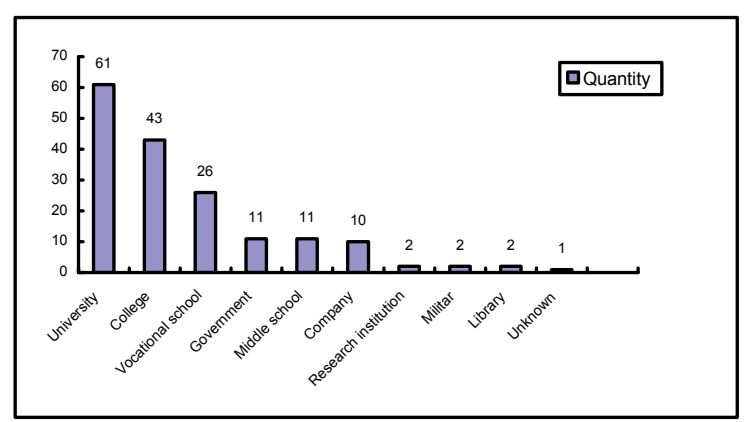

Figure 7. Statistical data on distribution of original authors. 


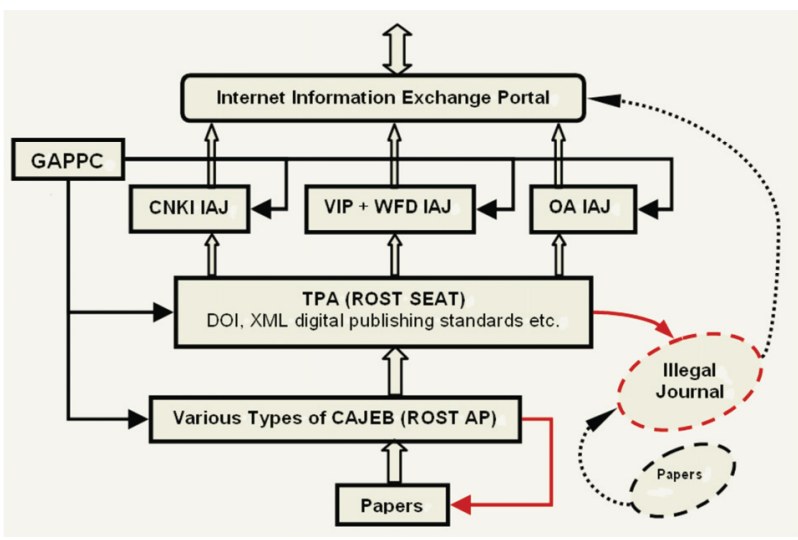

Figure 8. IAJ science information communication mode based on TPA.

obtained after scanning and OCR processing. The documents for displaying and download are in PDF format (with only CNKI has a unique CAJ format). When producing bibliographic information such as full-text indexes, authors, titles, affiliations, references, etc., no matter the process is conducted manually or assisted by software with manual inspection, the IAJs all choose to use different internal formats and never share with each other. Full-text reading is only limited to personal computers with PDF compatible software like Adobe Reader. Even the basic bibliographic information is only available to Internet Explorer (IE) based browsers, but does not support other browsers such as Firefox, Google Chrome or mobile Linux based browsers.

The three IAJs have experienced transition and expansion periods in aspects of scale \& category collection, technical support and sales income, and have stepped into a steady development stage. How to make use of the existing successful experience in China and foreign countries to further improve and expend Chinese IAJ construction based on Extensible Markup Language (XML) along with Hypertext Markup Language (HTML) as the core, is a common problem faced by all three IAJs.

\subsection{IAJ Management and Relevant Problems}

IAJs mainly obtain their information resources from CAJEBs which have paper copyrights with control. Economic benefits are distributed only between IAJs and CAJEBs, and there is no systematic restriction or supervision mechanism to guarantee authors' financial benefits. Another problem closely related to copyright problem is that the financial benefits produced by the same paper that is published by several IAJs and they cannot be effectively returned to the original author and CAJEB.

According to relevant national policy, after peer review and formal collection by CAJEB before publishing, CAJEBs often charge a certain amount of money from authors in the name of page fee, publishing fee or manu- script review fee (generally called publishing fee below). IAJs completely adopt a market-oriented operation and charge libraries and information institutions in universities, research institutes, enterprises, public institutions and individuals in variety of ways including Internet database packages, mirror site purchase, network flow and etc. After several years of operation, these IAJs show that each one operates in a reasonable status and gets a certain amount of profit annually which the profit keeps increasing. Although IAJs such as CNKI pay copyright royalties to CAJEBs like copyright usage fees for collected articles. As a matter of fact, CAJEBs seldom provide any payment to authors [11].

As a responsible or correspondent author of a paper, he/she has to pay a certain amount of money not only at the time to publishing, but also at time when reading. The subscription fee is although usually paid by the libraries or organization they work for. CAJEBs collect both of publishing fees from authors and copyright usage fees from IAJs. Every IAJ makes full use authors' academic efforts, while CAJEBs gain good financial profits, create excellent social benefit, and boost science information communication. However, the profit distribution among authors, CAJEBs and IAJs is obviously unfair and improper, especially from author perspective.

\section{IAJ Science Information Communication Mode Based on TPA}

\subsection{Improvement of IAJ Communication Mode}

From the view of economic scale, CNKI now gets the best enterprise benefit among the three IAJs. In 2005, its sales revenue was RMB 140 million Yuan (21.5 million US dollar) with a net profit of RMB 26 million Yuan (4 million US dollar), in which the overseas sales amount was more than RMB 32 million Yuan (4.9 million US dollar). Its fixed assets valued RMB 190 million Yuan (29.2 million US dollar) after years of accumulation. WFD ranked second and its sales revenue in 2005 was nearly RMB 200 million Yuan (30.7 million US dollar) with a slight worse net profit when compared to CNKI. Since 2003, VIP has had a steady average annual sales nearly RMB 30 million Yuan (4.6 million US dollar) with around RMB 1 million Yuan (0.15 million US dollar) net profit. In order to maximize the enterprise benefit, the principle of "survive the fittest" is inevitable. Under the competition mechanism of market oriented economy, enterprises merge, combination or acquisition are normal economy activities. If WFD and VIP, both of whose net profit are relatively small and are all managed by MSTC, can be merged to a large-scale VIP + WFD IAJ enterprise, the new enterprise may achieve the economic benefit by size-effect which is unavailable in current 
state. The new combined enterprise would gather resources and techniques to compete with CNKI, and then it could also provide better services for the science information community while creating a favorable condition for its own development.

Chinese open access (OA) IAJs have had some achievements after years of construction. Science Paper Online is a good example which has included 65 kinds of OA journals. Among Chinese OA IAJs, 4 of them have already indexed by Directory of Open Access Journal (DOAJ). However, the current scale cannot meet the need of internet based science information communications. Because domestic OA IAJs are not popular and low in influence, scientific researchers tend to submit to CAJEBs instead of OA IAJs although the publication cycles are relatively long. For example the IAJs like CNKI aimed to provide a fast track service usual cannot make a paper available online up to 2-4 months after the printed paper version. In this regard, it could be wise a wise model that third-party agencies finance independent OA IAJs and cooperate with CAJEBs. By learning from the operation experience of $\mathrm{OA}$ journals from foreign successful publishers, e.g., open Choice. Depending on authors' objectives and financial status, after approved peer-review by a CAJEB, OA IAJ fast publishing could be realized for scientific research papers. However, the authors have to pay a relatively higher fee to OA IAJs and CAJEBs in this condition. Certainly, existing IAJs including CNKI could provide real-time fast publishing while offering other integrated services. We suggest using an improved IAJ communication mode as shown in Figure 8.

In this improved science information communication mode based on IAJ, the TPA is an independent, fair and non-profit organization which, under the leadership of GAPPC. The GAPPC drafts policies and instructions, conducts coordination, produces publishing contents, XML standards, copyright management and profit distribution, and supervises illegal journals. The TPA then organizes coordinates, supervises and directs the science information and it also play a core role to improve existing science information communication mode. The major responsibilities include:

- To properly distribute journal resources among IAJs and avoid repeated collection of CAJEB resources.

- To establish relevant XML standard for IAJ for paper submission, text editing and IAJs' publishing.

- To accelerate anti-plagiarism software \& application development and restrict the further spread of paper dealing activates as well as illegal journals.

Although from the very beginning the three IAJs were supported by departments and commissions of the, they still substantially are non-state-owned IT enterprises taking sole responsibility for profits or losses. Their main commercial products are journals directed by GAPPC. In order to avoid repeated journal resources collection, one of the main tasks of a third-party agency is to coordinate and allocate journal resources according to different IAJs' expertise. For journals containing interdisciplinary subjects, mathematics and computer science which may serve as tools for other subjects, university journals and comprehensive journal resources, certain degree of reparation can be helpful. For example, the subscriber can find direct academic information and relevant information within one IAJ with an improved service quality like connection speed, cost-effectiveness and user experience. In 2007, in order to facilitate scientific researchers and IJ publishers' demand for a better XML capability, Microsoft provided an NLM DTD compatible add-in plug-in [12] for Word so the users can produce XML compatible documents when using normal Word documents. The implementation makes Word documents consistent with XML standard at any stage which is convenient for publishing, storing and knowledge transfer. For the issue that there are so many CAJEBs in China while the three IAJs have distinctive pushing methods, third-party agencies should agree to establish a common XML standard for software specifications, submission implementation, format conversion and IAJ historical data resources collection. The standard enables flexible editing, paper transfer and data share and also lays the foundation IAJ mobile computing applications.

The paper "buy and sell" is an indirect outcome of incomplete science information communication platform [13], which also reflects that China should make more effort on academic ethics system constructions. The 1AJ management mode based on thirty-party agency should be improved, while current anti-plagiarism system (ROST AP) [14] can be applied and further developed to enhance the capabilities for all kinds of journals. The GAPPC has taken a series of measures to deal with the issue. For example, it organizes dedicated professionals checking journals every year and has listed online illegal academic journals catalogues [15] to alert a group of lawbreakers \& public. However, these measures fail to put an end to paper dealing. We suggest third-party agency, together with academic institute, research related websites and search engines form an "Ally for Proper Academia Network", and jointly undertake the social responsibility for developing academic journals (ROST SEAT) [16] and cracking down the business. Law policies may be produced by organizations such as Chinese Law on Academic Norms and Global Academic Ethics to further regulate illegal journals.

\subsection{IAJ Copyright Management Mode Based on TPA}

The copyrights of various resources collected by IAJs are usually owned by domestic CAJEBs. IAJs must obtain 
rights from owners such as copyrights so as to legally publish these printed academic papers in IAJs.

Collective copyrights management means that Copyright owners including neighboring right owners authorize collective copyright management organization to manage their rights. Such an organization supervises the work usage, negotiates the conditions of usage with potential users, produces usage licenses, collects subscription fees and distributes the fees among copyright owners [17]. The academic paper copyright management can be regarded as one kind of CAJEBs based collective copyrights management. It facilitates flexible copyright management and realizes legal Internet variety publishing e.g. the same paper can be published by several publishers. It also increases science information communication channels, intensifies competition for service quality and embodies copyrights collective management advantages.

The core idea of the third-party copyright management mode is that authors possess copyrights but entrust thirdparty copyright management organization to manage their paper ownerships and related issues. The organization gives an exclusive publishing license to CAJEB: during a certain period, other publishers are not allowed to publish the papers in any form (printed or online edition, etc.), and the length of period can be changed according to factors such as publication type. The thirdparty copyright management organization is the only legal copyrights owner of all kinds of papers (printed or online edition, etc.) in terms of publishing, who takes charge of copyright management (including licenses, conditions and supervision), adjusts paper publishing priorities at CAJEBs and IAJs, and assists to establish the beneficiary payment mode of the TPA. Each IAJ must contact third-party copyright management organization to obtain a license for Internet publishing.

\subsection{Third Party-Based Beneficiary Pay Mode in IAJ}

The essence of beneficiary pay mode is that, beneficiaries jointly pay the publishing fees for scientific research efforts and rewards contributed authors. Based on beneficiary pay mode [18], a third party-based beneficiary pay mode has been moved forward. The following aspects are applied to boost science information communication system on both CAJEBs and IAJs:

- Determination of beneficiaries and beneficial degree: Authors, subscribers and IAJs are beneficiaries of published papers. For the subscribers' perspective, they may get information needed from IAJ websites directly or obtain the information from IAJ citation analysis platforms. Published papers from authors are the core resource and foundation for IAJ opera- tions which attract users therefore IAJ and authors are also beneficiaries.

- Payment subjects and objects: The subjects of payment are beneficiaries and objects of payment are authors and CAJEBs in the science information domain. Printed journals determine the submitted papers academic values and claim publishing rights for authors' scientific research results. Authors first pay publication fees to CAJEB. When subscribers publish their own scientific research papers with references, the appreciation is expressed by paying the authors, who are cited in references a certain amount of money. It is seen as a tribute to others' scientific research efforts and is a necessity for establishing a people-oriented scientific research environment. The usage of scientific research results by enterprise customers is seldom embodied in published papers and it is hard to determine such kind of usage from references. IAJs should adopt a different charging tariff for those subscribers, properly raise the use price and promote science information communication mechanisms from which they benefit more. Although IAJs do not obtain copyrights directly from authors, the fact is that authors provide the core contents. IAJs can trust CAJEBs or use other methods to manage copyrights, but it is better to bypass CAJEBs and pay authors directly to reduce administration cost.

- Subscription fees distribution. Authors should pay publication fees to journal editorial boards and IAJs. The fees include two parts: manuscript review fee which should not be over-charged as many potential authors may withdraw; the page processing fee which is paid after peer-review, paper revision and acceptance notification. A public credible independent third-party agency is needed to collect basic IAJ usage fees from universities and colleges, research institutes, enterprises and government based on usage date fetched from mirror sites, Inter- net database packing and data flow. It also collects a certain amount of use fees from authors or subscribers who cite others' literatures according. The payment of operations, maintenance, new technology development and some commercial profit to IAJs are based on publication contents, papers download and references count.

The beneficiary pay mode introduction based on TPA requires a longer term follow up and should experience academic value verification. As for all contributors, there should be a fair benefit distribution mechanism to encourage authors and at the same time to guarantee the financial interests and brand effects for publishing institutions including IAJs and CAJEBs so that a healthy operation can be maintained. We suggest that a fair, credi- 


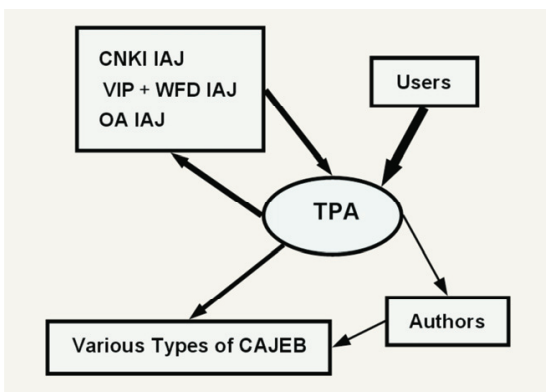

Figure 9. Beneficiary payment mode of TPA.

ble and independent TPA accelerate this progress to boost internet based science information communications. The TPA also prevents authors becoming the vulnerable group in the chain. Please refer to Figure 9 for the beneficiary payment mode.

\section{Conclusions}

Building Chinese Internet academic journals for science information communications based on the TPA is a systematic engineering work, for which the advance in science and technology must be accelerated through system innovation. To deepen the technological system reform and all supporting system reforms, a vigorous system model that facilitates the innovation progress should be adopted increase productivity, embody Internet journals with Chinese characteristics, and conform to the technological development rule.

By learning the achievements of various Chinese IAJs and Chinese OA journal practice, several issues and operation models for digital publishing has been discussed. The benefit distribution and copyright management mode based on the TPA is proposed and studied. The future IAJs operation mode is also discussed from the view of innovative scientific research service and platform construction obstacles.

\section{References}

[1] L. F. Xu, "Digital Information Communication," Wuhan University Press, Wuhan, 2008.

[2] J. Willinsk, "Proposing Knowledge Exchange Model for Scholarly Publishing," Current Issues in Education, Vol. 3, No. 6, 2009. http://cie.asu.edu/ volume3/ number6/
[3] X. X. Shen, Z. Zheng and C. Shen, "A Review of the Major Projects Constituting the China Academic Digital Library," The Electronic Library, Vol. 26, No. 1, 2008, pp. 39-51.

[4] CERNET Network Center, "CERNET Brief Introduction," 2009. http://www.edu.cn/ cernet_jian_jie_1327/200 60323/t20060323_91159.shtml

[5] STNET Network Center, “About CSTNET," 2009. http:// www.cstnet.net.cn/ about.jsp?Type $=$ zxgk

[6] J. K. Wang, "Web Publishing Resources out of a Possible Integration of the Road," China Culture Daily, 2006.

[7] CNKI, "CNKI Topology for Database Exchange Service Centre," 2009. http://www.dl.cnki.ne/tgycnki/daobao/cnkidaobao4/daobao2-5.htm

[8] CNKI, “About CNKI,” 2009. http://www.global.cnki. net/Grid20/Aboutus/Aboutus.htm

[9] S. Tokizane, "Electronic Journal Publications in China," Journal of Information Processing and Management, Vol. 50, No. 1, 2007, pp. 2-10.

[10] Z. Hao, et al., "2006-2007 Interpretation for Annual Report on Publishing Industry in China," China Books Press, Beijing, 2007.

[11] S. Z. Chen, "On Copyright Protection of Journal," Journal of Zhejiang Police College, Vol. 8, No. 2, 2006, pp. 106-108.

[12] Microsoft, "Article Authoring Add-in for Microsoft Office Word," 2009. http://www.microsft.com/downloads/ details.aspx?FamilyId=09C55527-0759-4D6D-AE0251E90131997E\&displaylang=en

[13] G. J. Shi, "On the Modern Science and the Exchange of Structure and Function of Innovation," Science and Technology Progress and Policy, Vol. 22, No. 1, 2005, pp. 1418.

[14] Y. Shen, et al., "Research of Anti-Plagiarism Monitoring System Model," Wuhan University Journal of Natural Sciences, Vol. 12, No. 5, 2007, pp. 1202-1209.

[15] GAPPC, "Illegal Journals on the List of Notification," 2009. http://218.7.112.124/Article_Show.asp?ArticleID= 627

[16] Y. Shen, et al., "Introducing a Metadata Earch EngineROST SEAT," 2009. http://hi.baidu.com/whusoft/blog/ item/174090168e3b771c972b432e.html

[17] C. J. Wang, "Intellectual Property Right of Electronic Periodical in China," Shanxi Library Journal, Vol. 23, No. 1, 2007, pp. 3-6.

[18] T. Ohta and K. Hayashi, "Innovation-Oriented Publication System," Journal of Information Processing and Management, 2005, Vol. 48, No. 11, pp. 717-722. 